\title{
Violencia política y represión en América Latina
}

En primer lugar cabe aclarar que el contexto de producción de este número de Estudios registró sus esfuerzos en las peculiares condiciones impuestas por la pandemia global, con la consiguiente limitación de las actividades universitarias a la lógica de la virtualidad. La impronta de esta situación excepcional habilitó la inclusión de un dossier con aportes provenientes de México (Universidad de Guanajuato), Uruguay (Universidad de la República) de la Universidad Nacional de Rosario y del CONICET.

Centrado en el tema de la violencia política y la represión, los textos que componen este número extienden su mirada a diversas provincias: Córdoba (un trabajo sólidamente documentado echa luz al funcionamiento de la maquinaria burocrática del Estado durante la última dictadura), Mendoza (donde se analiza el PRT-ERP y el papel jugado por los cuadros cordobeses en su proceso de construcción), Chaco (que retrata la represión política en el mundo rural a través del devenir del cooperativismo y las ligas agrarias) y Buenos Aires (desde una perspectiva que hundiendo sus raíces en el pasado propone una lectura renovada y erudita de la semana trágica de 1919).

Incluye, asimismo, aportes provenientes de la historia oral (a través de la interpretación del testimonio de Sara Waitman), un estudio de las representaciones y justificaciones de los dictadores derrotados y juzgados (sus «mantras» de legitimación) y dos artículos que remiten a la dictadura militar de Augusto Pinochet en Chile: uno centrado en los bandos de la Junta Militar y otro que dibuja los derroteros de la represión extraterritorial del pinochetismo durante el período democrático iniciado por la presidencia de Raúl Alfonsín en Argentina, tema de particular interés en nuestro país que permite evocar una modalidad de represión que tenía como antecedente el asesinato del líder democrático del ejército chileno, el general Prats, en 1974 durante el tercer gobierno peronista.

Tres comentarios bibliográficos acordes con la temática del número, uno de Alicia Servetto (CEA-FCS-UNC), otro de Florencia Gandara 
(UNSAM) y un tercero de Fira Chmiel (UNSAM-CONICET) cierran la presente edición.

En su conjunto, las contribuciones presentes aportan nuevos elementos para el análisis de un pasado presente en las preocupaciones políticas, intelectuales y morales de las nuevas generaciones de jóvenes investigadores interesados en develar las claves de la violencia política y la represión estatal en el mundo contemporáneo.

César Tcach

Director de Estudios 